\section{Cortical Bone Modifications after Radiotherapy: Cortex Porosity and Osteonal Changes Evaluated Over Time}

Juliana Simeão Borges ${ }^{1}$ (D), Gustavo Davi Rabelo² ${ }^{\mathbb{D}}$, Milena Suemi Irie ${ }^{\mathbb{1}}$,

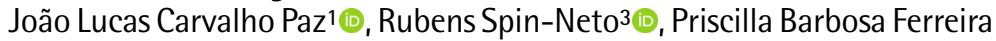
Soares ${ }^{1}$ (i)

Aiming to evaluate cortical bone microarchitecture and osteonal morphology after irradiation, twelve male New Zealand rabbits were used. The animals were divided: control group (no radiation-NIr); and 3 irradiated groups, sacrificed after: 7 (Ir7d); 14 (Ir14d) and 21 (Ir21d) days. A single radiation dose of $30 \mathrm{~Gy}$ was used. Computed microtomography analyzed the cortical microarchitecture: cortical thickness (CtTh), bone volume (BV), total porosity (Ct.Po), intracortical porosity (CtPo-cl), channel/pore number (Po.N), fractal dimension (FD) and degree of anisotropy (Ct.DA). After scan, osteonal morphology was histologically assessed by means: area and perimeter of the osteons (0.Ar; 0.p) and of the Haversian canals (C.Ar; C.p). Microtomographic analysis were performed by ANOVA, followed by Tukey and Dunnet tests. Osteon morphology analyses were performed by Kruskal-Wallis, and test Dunn's. Cortical thickness was significant difference $(p<0.010)$ between the NIr and irradiated groups, with thicker cortex at Ir7d $(1.15 \pm 0.09)$. The intracortical porosity revealed significant difference $(p<0.001)$ between irradiated groups

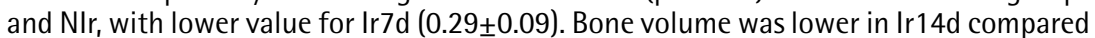
to control. Area and perimeter of the osteons were statistically different $(p<0.0001)$ between NIr and Ir7d. Haversian canals also revealed lower values $(p<0.0001)$ in Ir7d $(80.57 \pm 9.3 ; 31.63 \pm 6.5)$ compared to NIr and irradiated groups. Cortical microarchitecture was affected by radiation, and the effects appear to be time-dependent, mostly regarding the osteons morphology at the initial days. Cortex structure in Ir $21 \mathrm{~d}$ revealed similarities to control suggesting that microarchitecture resembles normal condition after a period.
'Periodontology Department, Faculty of Dentistry, UFU Universidade Federal de Uberlândia, Uberlândia, MG, Brazil

2Dentistry Department, UFSC: Universidade Federal de Santa Catarina, Florianópolis, SC, Brazil 3Dentistry Department and Oral Health, Oral Radiology Department, Aarhus University, Aarhus, Denmark

Correspondence: Priscilla Barbosa Ferreira Soares, Avenida Pará s/ $\mathrm{n}^{\circ}$, Bloco 4L, anexo A, 38.400902 Uberlândia, MG, Brasil. Tel: +55-34-3225-8106. e-mail: pbfsoares@yahoo.com.br

Key Words: ionizing radiation, cortical bone, microarchitecture, haversian canals.

\section{Introduction}

lonizing radiation therapy used in radiotherapy (RT) in combination with surgical procedures are the main treatment modalities for malignant tumors (1). When the bone is included in the irradiated field, initial changes directly affect bone remodeling activity (2). Therefore, high-dose irradiation causes irreversible side-effects on the tumor surrounding healthy tissues. These injuries lead to impairment in bone repair properties that could progress to complications, such as infections, healing delay and osterradionecrosis (3). Previous publicatios from our group showed the effects of RT on cortical bone that revealed modification on the morphology of bone channels network (4), decreased anisotropy and increased bone fragility (5), also with deficity in bone quality, with decrease of stiffness, more evident in later time points after radiation (6).

The cortex comprises the majority of the appendicular skeleton (7), and as this bone part is known to be altered after RT, a major interest on the principal unit of the cortical bone - the Osteon - has increased. Osteons could be primary and secondary (8). Besides osteonal structure, cortical bone is considered not fully compact, once the structure is traversed by many Haversian (at the center of the osteons) and Volkmann canals. All of these canals have in their surfaces the lining that provide a surface area for remodelling (9). In humans, about half of cortical bone loss at peripheral sites was the result of remodelling within the cortex adjacent to the marrow (9).

Regarding bone quality within the cortex and remodeling, larger osteons may favour crack propagation increasing bone toughness, whereas smaller osteons may favour a crack propagation with low resistance to fracture (10). These cracks, a type of bone microdamage, are considered target for remodeling $(11,12)$. The secondary osteons of cortex are formed by two sequential processes and the remodeling extends from the endosteum to the subperiosteal lamellar systems (13). The geometry of the osteon has an important role in a resistance to deformation (14), and the influence of osteon geometry and composition on bone fragility is not fully understood (10).

Therefore, the aim of this study was to evaluate the cortical bone microarchitecture and the morphological characteristics of osteons after a single-dose (30 Gy) 
of ionizing radiation, also comparing modifications on different periods after radiation exposure.

\section{Material and Methods}

\section{Study Design}

Twelve male New Zealand rabbits (Oryctolagus cuniculus) weighting $3.0-3.5 \mathrm{~kg}$ were randomly divided into four groups of three animals each. All animals were acclimatized for 2 weeks previously to experimental procedures and individually housed in standard cages containing bedding and nesting material at $20^{\circ} \mathrm{C}$ under controlled humidity and a light/dark cycle of $12 \mathrm{~h} / 12 \mathrm{~h}$. The diet consisted of standard laboratory pellets and water ad libitum. The animal caretakers were blind to the experimental groups. Both legs from each animal were included in the study, totalizing six tibias per group $(n=6)$. The animals were divided into 4 groups: non-irradiated rabbits (NIr; control group), and irradiated rabbits (Ir), sacrificed at different times, as follows: group Ir7d (euthanized at 7 days after the radiation procedure), group $\operatorname{Ir} 14 d$ (euthanized at 14 days after the radiation procedure) and group Ir21d (euthanized at 21 days after the radiation procedure). The Institutional Animal Care and Use Committee of the institution approved all procedures (Protocol: 093/12), in compliance with Ethical Standards.

\section{Irradiation Procedure}

During the RT session, the animals (Ir groups) were kept under general anesthesia with an intramuscular injection of a combination of $0.25 \mathrm{mg}$ of ketamine/ $\mathrm{kg}$ (Ketamina Agener $^{\circledR}$; Agener União, São Paulo, SP, Brazil) and $0.5 \mathrm{mg}$ of xylazine $/ \mathrm{kg}$ calculated for this dose per body weight (Rompum ${ }^{\circledR}$ Bayer, São Paulo, SP, Brazil). The left and right hind legs of each rabbit were subjected to a single dose of $30 \mathrm{~Gy}$. The total dose of $30 \mathrm{~Gy}$ is considered adequate to produce compromised surgical bed, simulating in rodents the clinical situation observed in humans (15).

Animals were placed in the supine position and the left and right hind legs were positioned and fixed laterally using a wooden stick and adhesive tape. A wax bolus was placed over the area and the tibia was irradiated in a single anterior field. A dose of radiation was delivered with a source-skin distance of $60 \mathrm{~cm}$ and the field size was $15 \times 15 \mathrm{~mm}$, with direct electron beam of $6 \mathrm{MeV}$ electrons (Varian $600-\mathrm{C}^{\circledR}$ Varian Medical Systems, Palo Alto, California, EUA). After radiation, the responsible veterinarian closely monitored the skin, hair, weight, and appetite of the rabbits. The animals were sacrificed by an overdose of anesthetic ( 0.75 $\mathrm{mg}$ of ketamine/ $\mathrm{kg}$ of body weight). Animals of the control group were sacrificed at $\mathrm{t} 0$, which means, at the day 0 . In the irradiated groups, the sacrifice was planned at 7 , 14 and 21 days after radiation. The overlying soft tissues were removed, and the tibias were stored in phosphate buffered saline solution and frozen at $-20{ }^{\circ} \mathrm{C}$ in plastic tubes (Cralplast 17000, São Paulo, SP, Brazil).

\section{Micro Structural Analysis by Micro-CT}

The samples were stored frozen at $-20{ }^{\circ} \mathrm{C}$ for $48 \mathrm{~h}$. For assessing the tridimensional (3D) bone microarchitecture, the tibia diaphysis (Fig. 1A) was examined using a microcomputed tomography analyzed ( $\mu \mathrm{CT}$; SkyScan 1272, Bruker, Kontich, Belgium). During scanning, the tibia was placed in the polyethylene tube avoiding movements and dehydration. The scanning parameters were $15 \mu \mathrm{m}$ pixel size, $50 \mathrm{kVX}$-ray voltage, $160 \mathrm{~mA}$ electric current and using a $0.5 \mathrm{~mm}$ Al filter. Subsequently, the reconstructed 3D data sets were obtained and quantified using NRecon and CTAn automated image analysis system (Fig. 1B). Cortical bone was segmented manually on a slice-by-slice basis by a single expert operator (Fig. 1C). After that, the volume of interest (VOI) for cortical analyses was selected and extending 300 slices in total for each tibia, and a global bone threshold (55 lower grey threshold and 255 upper grey threshold) it was obtained (Fig. 1D). The following parameters were measured in the cortices: mean thickness (Ct.Th, $\mu \mathrm{m}$ ); total porosity (Ct.Po, \%); closed porosity (just considering the intracortical pores, Ct.Po (cl), \%); Haversian channel/ pore number (Po.N); bone volume (BV, mm3); degree of anisotropy (Ct.DA, \#); and fractal dimension ( $F D, \#)$, analyzed using CTAn software (Skyscan, Bruker, Belgium).

\section{Micro Structural Analysis by Histological Sections}

After scan and in order to determine the osteonal morphology, the samples were decalcified in 10\% formic acid solution for 15 days, and then processed and embedded

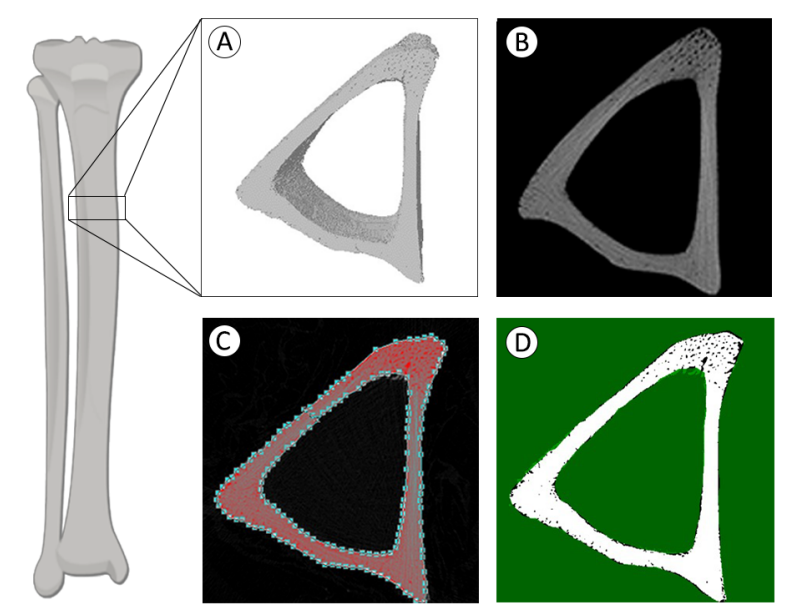

Figure 1. Microtomography computadorized (MicroCT) image of bone structure. A: Cortical bone microarchitecture of the tibia diaphysis; B: Slice of the reconstructed volume in an axial view; C: Manual segmentation performed on a slice-by-slice basis; D: Definition of a global bone threshold. 
in paraffin. Histological sections were obtained as $5 \mu \mathrm{m}$ thick sections, counting 3 sections per sample. All sections were stained with hematoxylin and eosin (H\&E). Digitized images of each sample were captured at 10x magnification using a Nikon Eclipse E2000 binocular microscope (Nikon, Sao Paulo, Brazil) along with a Moticam Pro 252B camera and the Motic Live Imaging Module software (Motic ${ }^{\circledR}$, British Columbia, Canada). These images were inserted to the ImageJ software (ImageJ, 1.45q, National Institutes of Health, USA) (Fig. 2), and the area and perimeter of osteons and Haversian canals were measured manually. The osteons within the image were randomly chosen, respecting the exclusion criteria: non-totally visible osteons within the measurement region; a non-circular/ oval format of the inside channel; unidentifiable limits and too small size (as smaller as the visually mean of the other osteons within the image). The following parameters were obtained: Osteon area (0.Ar in square micrometer), Osteon perimeter (0.p in micrometers), Haversian canal area (C.Ar in square micrometers) and Haversian canal perimeter (C.p in micrometers). At least 20 osteon including vascular channels in their middle were measured for each group.

\section{Statistical Analysis}

The mean thickness (Ct.Th), total porosity (Ct.Po), closed porosity (Ct.Po (Cl)), pore number (Po.N), bone volume (BV); degree of anisotropy (Ct.DA) and fractal dimension (FD), data were tested for normal distribution (Shapiro-Wilk) and equality of variances (Levene's test), followed by parametric statistical tests. One-way analysis of variance (ANOVA) was performed for all data. Multiple comparisons were made using Tukey's test for comparison between irradiated groups on different periods and Dunnet test was used for comparison between control group and

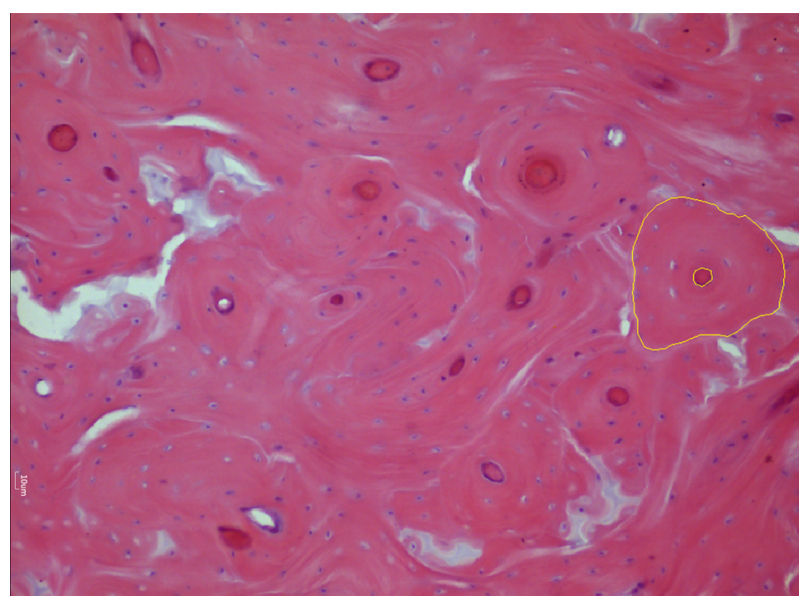

Figure 2. Histological assessment of the osteons morphology (Hematoxilin and Eosin stain. Original Magnification of 20X). Delimitation of the Osteon and Haversian canal (in yellow). Measurements were obtained using ImageJ software. irradiated groups. Sample size was grounded on information from previous reports applying similar animal model. A post-hoc test was performed to define the minimum difference in the parameters assessed herein that would have been possible to detect applying a power of $80 \%$ and an alpha error of $0.05 \%$. The Osteon area (0.Ar), Osteon perimeter (O.p), Haversian canal area (C.Ar) and Haversian canal perimeter (C.p) were tested for normal distribution (Shapiro-Wilk), followed by nonparametric statistical test (Kruskal-Wallis) and multiple comparison test (Dunn's). All tests employed $\alpha=0.05$ significance level and all analyzes were carried out with the Statistical Package for Social Sciences version 15 (SPSS Inc., Chicago, IL). In addition, intraclass correlation coefficient (ICC) was calculated for the osteonal morphology analysis, being analyzed 20 osteons per group after a time interval in order to test the intra-rater reliability (0.995).

\section{Results}

Clinical evaluation of the animals during the procedure revealed that irradiated rabbits developed alopecia due to radiotherapy. No animal or leg was lost in the study. Concerning $\mu \mathrm{CT}$ results, cortical thickness was significant different $(p<0.010)$ between NIr $(1.01 \pm 0.04)$ and the Ir7d irradiated group, with thicker cortical bone on the experimental group (1.15 \pm 0.09$)$. Among irradiated groups, the cortex was thicker at 7 compared to 14 days $(1.01 \pm 0.05)$, but similar to the 21 days $(1.07 \pm 0.09)$ (Fig. $3 \mathrm{~A})$.

There was no difference for the total cortical porosity for all groups (Fig. 3B). However, the intracortical porosity (closed porosity), represented by only the intracortical channels, revealed significant difference $(p<0.001)$, among the irradiated groups, with lower value for the Ir7d group $(0.29 \pm 0.09)$, compared to $\operatorname{Ir} 14 d(0.48 \pm 0.08)$ and Ir $21 d$ $(0.44 \pm 0.06)$ (Fig. 3 C). In addition, the intracortical porosity was also different $(p<0.001)$ between Ir7 $d$ and NIr group (0.53 \pm 0.18$)$ (Fig. 3C).

Fractal dimension (Fig. 3D) and degree of anisotropy (Fig. 3E) were not different between Nlr and irradiated condition, and among the irradiated groups. Bone volume was lower $(p<0.001)$ at 14 days $(92.06 \pm 6.34)$ compared with: control group (108.16 \pm 8.95$)$, and with both other irradiated groups, at 7 days $(114.37 \pm 12.15)$ and 21 days (120.36 \pm 6.09$)$ (Fig. 3F).

The osteons area (0.Ar), and perimeter (0.p) mean and standard deviation values are shown in Figure $4 \mathrm{~A}$ and $4 B$, respectively. Tukey test showed that NIr group had significant higher values for both parameters (O.Ar: $3347.0 \pm 149.0$; 0.p: $210.7 \pm 54.6)$ than Irradiated group measured at 7 days (0.Ar:1490.0 $\pm 78.7 ; 0 . p: 142.0 \pm 35.2$; $p<0.001)$. Among the irradiated groups, the area and perimeter measured at 7 days were significantly lower than 

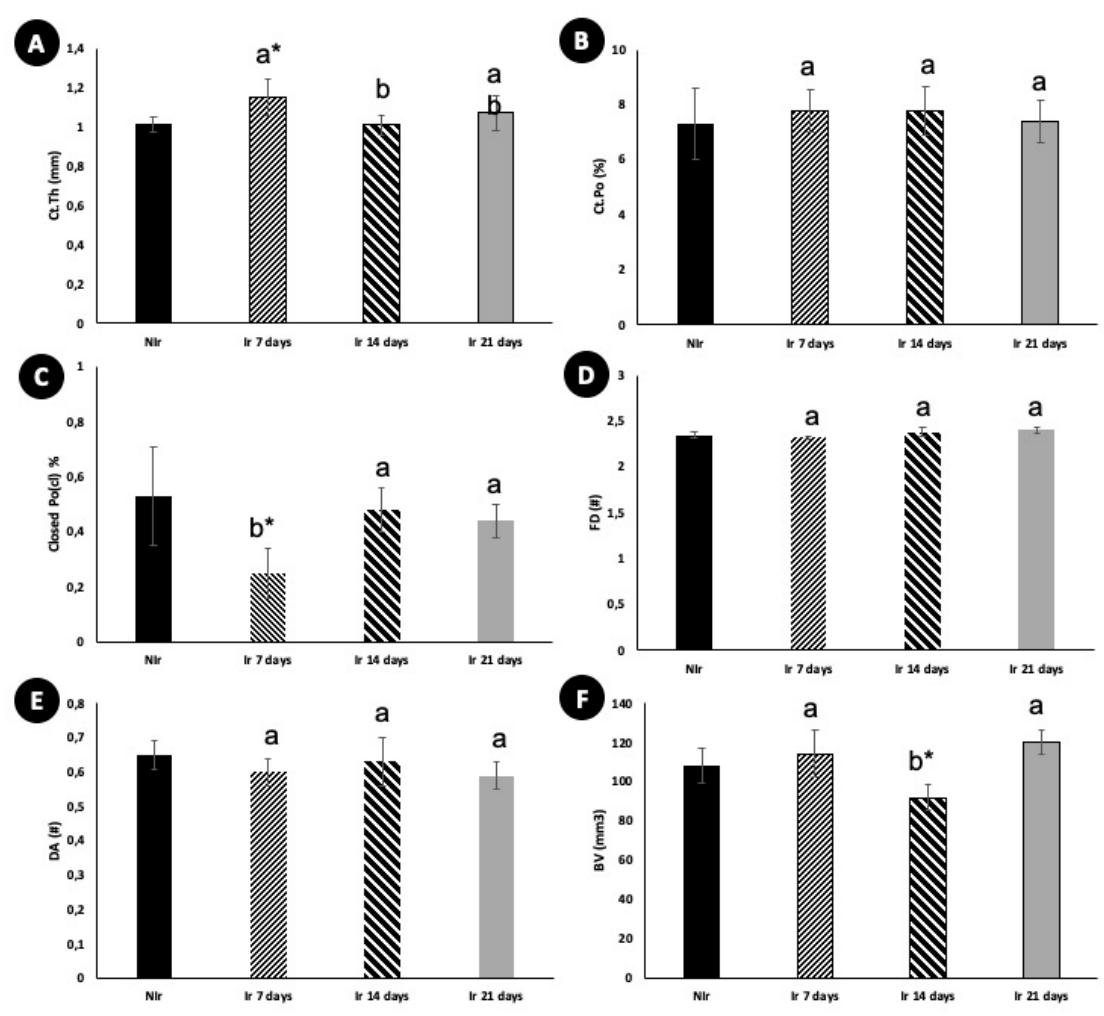

Figure 3 Mean and standard deviation values of morphologic parameters measured by Microtomography computadorized (MicroCT) for non-irradiated bone (control group) and irradiated bone after different periods (7, 14 and 21 days). A: Mean thickness - Ct.Th in mm; B: Total porosity - Ct.Po in \%; C: Closed porosity - Ct.Po in \%); D: Fractal dimension - FD; E: Degree of anisotropy - Ct.DA; F: Bone volume - BV in mm3. Different letters mean significant difference between irradiated groups (Tukey test; $p<0.05$ ). * significant difference between the non-irradiated group and control group (Dunnet test; $\mathrm{p}<0.05$ ).

presented the smaller Osteons with more variable shapes among all groups (Fig. 5C), also accompanied with the most heterogeneous interstitial bone, revealed by amorphous basophilic areas and no lamellae organization (Fig. 5D).

\section{Discussion}

This study evaluated the cortical bone after a single-dose radiation therapy (30Gy) in rabbit's tibias at 7 , 14 , and 21 days after irradiation, using a high-resolution imaging technique followed by histological analysis. The results revealed an increase in cortical thickness after irradiation in the first period analyzed, followed by a decrease of the thickness after this period. Intracortical porosity decrease drastically in the first period of 7 days, and then increased in the following periods, possibly demonstrating a recovery in channels number over time. After irradiation, bone volume was decreased just in 14 days, different from 7 and 21 days. Going along with imaging results, osteons morphology also revealed changes related to the heterogeneity

at 14 days (0.Ar: $2890.0 \pm 152.7 ; 0 . p: 196.9 \pm 51.6 ; p<0.001)$ and 21 days $(3695.0 \pm 253.5 ; 216.0 \pm 75.2 p<0.001)$.

The area and perimeter of the Haversian canals mean and standard deviation values are shown in Figure $4 \mathrm{C}$ and 4D. Tukey test showed that NIr group had significant higher values both parameters (C.Ar.: $365.2 \pm 40.2$; C.p.: $65.5 \pm 17.9$ ) than Ir7days group (C.Ar.: $80.5 \pm 9.3 ;$ C.p.: $31.6 \pm 6.5 ; p<0.001$ ) and Ir14days (C.Ar.: $188.7 \pm 35.8$; C.p.: $43.7 \pm 9.5 ; p<0.001$ ). Among the irradiated groups, the area and perimeter of the Haversian canals were significantly smaller at 7 days compared with 14 days $(\mathrm{p}<0.001)$; and were significantly higher at 21 days $(398.2 \pm 33.3 ; 71.8 \pm 16.4 ; p<0.001)$.

To better represent histological results regarding osteons and Haversian channels, a schematic illustration was created with 3 possible osteon designs for each group (Fig. 5A, C, E and $\mathrm{G}$ ). Histological images that match these designs were chosen for all groups (Fig. 5B, D, F and H). Based on the standard deviation values variability, the outer surface of the osteons and their sizes variation, accompanied with the variation on the canals format, were found to range from round to oval design, containing canals ranging from higher to smaller diameters (Fig. 5). Ir7days group in their sizes and morphology, demonstrating an initial modification, probably related to a remodeling process. The size of the osteon was found to be smaller in the first period analyzed and increased in size in the subsequent periods, after radiation. Osteon perimeter also decreased in the first days, followed by recovery in 14 and 21 days. The standard deviation of osteon perimeter at all groups revealed that their design remained uniform, however different among them. Haversian channels also were smaller in irradiated group at 7 days, as well revealing a tendency to reach higher sizes and different design at 14 days, and more evident at 21 days, with similar results with the control group in this last-mentioned period.

In this study, the animal model used to assess cortical characteristics were the rabbit tibiae, a very well-established model for assessing bone biological and biomechanical characteristics (16). Bone metabolism of rabbits is 3 to 4 times faster than human; therefore, they are commonly used as animal model to evaluate the effects of radiotherapy in bone tissue (17). By the difficulty inherent to animal manipulation, the animals were exposed to just one dose of ionizing radiation, also described in other studies $(5,18)$, 

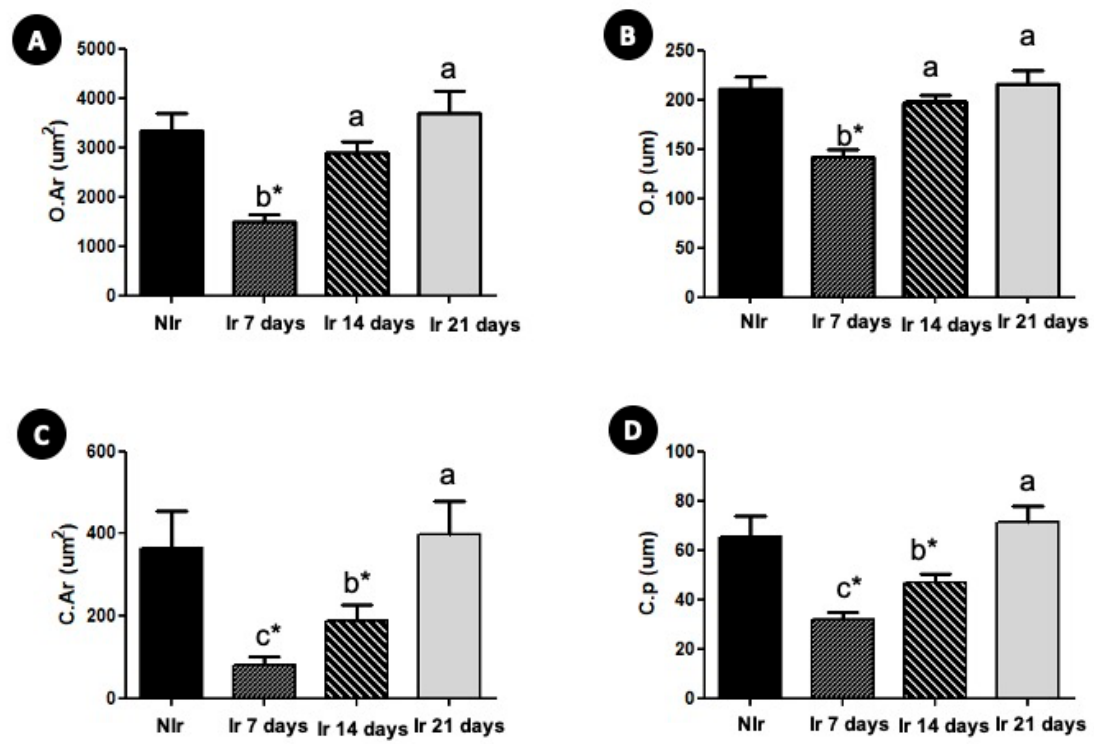

Figure 4 Mean and standard deviation of the osteons and Haversian channels measurements for non-irradiated (control group) and irradiated groups (7, 14 and 21 days): A: Osteon area, $0 . A r$ in $\mu m^{2}$; B: Osteon perimeter, 0.p in $\mu \mathrm{m}$; C: Haversian canal area, C.Ar in $\mu^{2}$; D: Haversian canal perimeter, C.p in $\mu \mathrm{m}$. Different letters mean significant difference (Kruskal-Wallis test; $\mathrm{p}<0.05$ ). ${ }^{*}$ significant difference between the non-irradiated group and control group (Dunn test; $p<0.05$ ).

Regarding osteons characteristics and vascular canals morphology (Haversian channels), our study observed smaller channels at 7 days after irradiation compared to the non-irradiated group. Geometric indices of the osteons estimate resistance to compression, bending and buckling based on their size (10). Also, some studies have demonstrated that ionizing radiation can cause endarteritis and vascular occlusion $(21,22)$. Once the intracortical porosity was lower at 7 days, the histological assessment also confirmed the imaging $\mu \mathrm{CT}$ results, revealing smaller channels in histological sections.

Osteons presented smaller sizes after irradiation, accompanied with a pronounced

where the exposition of the animals to a dose fractionation was not possible. Also, lower doses administered in a fractionated scheme do not seem to have as much an effect on cortical bone strength as a single large dose (19), so not adequate to our purposes in the approach to identify cortical alterations due to radiotherapy.

Cortical porosity and thickness were found to be different at 7 days. Was an interesting fact to discover an increase in the whole cortical thickness, accompanied to a decrease in intracortical porosity, the last one related to bone channels network. Cortical porosity has an impact on bone material and mechanical properties, as well as play a role in the remodeling process. Porosity is associated with bone channels and resorption areas within the cortical bone and consists in its majority part of a network of canals which provide space for the vasculature in the cortices, and also, to nourish the osteocytes (20). Therefore, our finding revealed a decline in the number of intracortical pores at 7 days after irradiation, might reflecting activity on bone turnover in the initial period after radiation exposure. Intracortical porosity tend to be similar to the control group in both Ir14d and Ir21d groups, suggesting that a regular process of bone turnover may take place at these periods. Also intriguing, the lower value for intracortical porosity of Ir7d group was surprisingly interesting, once there was more bone matrix at this period (represented by higher cortical thickness). Along with all data reported, this result suggests a direct effect on bone matrix together with effects on vascularization. heterogeneity concerning their contour and the interior channels size and shape. All osteons analyzed in our study revealed a lamellae organization formed by cylindrical and round structure in layers around the channels. It is known that secondary osteons consist of cylindrical units comprising several lamellae layers that are generally coaxial with the axis of the Haversian (or vascular), canal around which they form. Thus, Haversian system shows morphological heterogeneity that depends on the age of the individual, skeletal site and presence or absence of systemic factors that can alter the bone tissue (23). In this way, it could be supposed that in all groups in our study the bone was major composed by secondary osteons, and that their morphology is dependent on the vascular channels and on the remodeling process.

Interstitial bone was found to be also irregular, amorphous, and revealing very distinguish color, represented by basophilic areas in the majority areas filled with this bone (Fig. 5). These findings suggest that at 7 days, remodeling process occurred and was sufficiently pronounced to reach the whole cortical extension. Also, both osteon and interstitial bone morphology highly varied in the first period analyzed after irradiation, suggesting previous remodeling process that changed the microarchitecture. Well-designed osteon may be produced by the regulation of bone apposition by osteocytes during osteon refilling, and also that osteon size is determined by the quantum of bone removed by osteoclasts (24). In addition, our results also work as an indicator of different levels of mineralization 


\section{A $\mathrm{NIr}$}

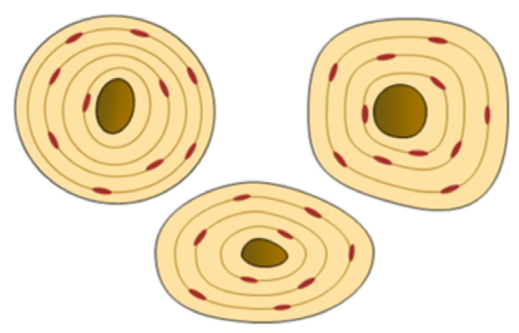

C Ir 7 days

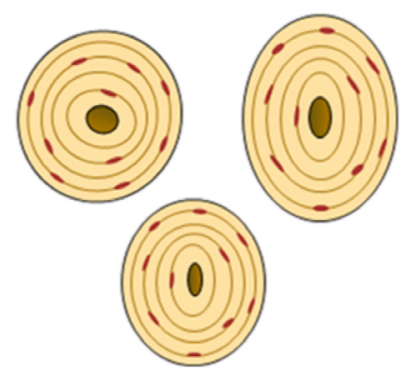

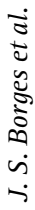

E Ir 14 days

\section{B $\mathrm{NIr}$}

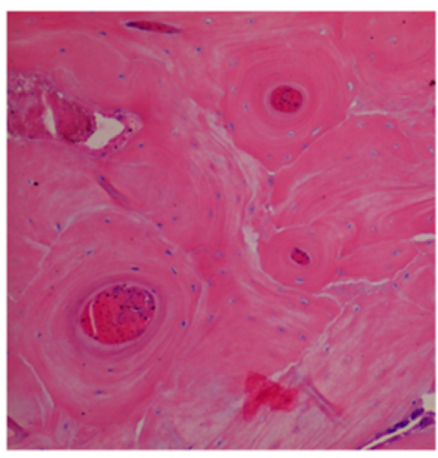

D Ir 7 days
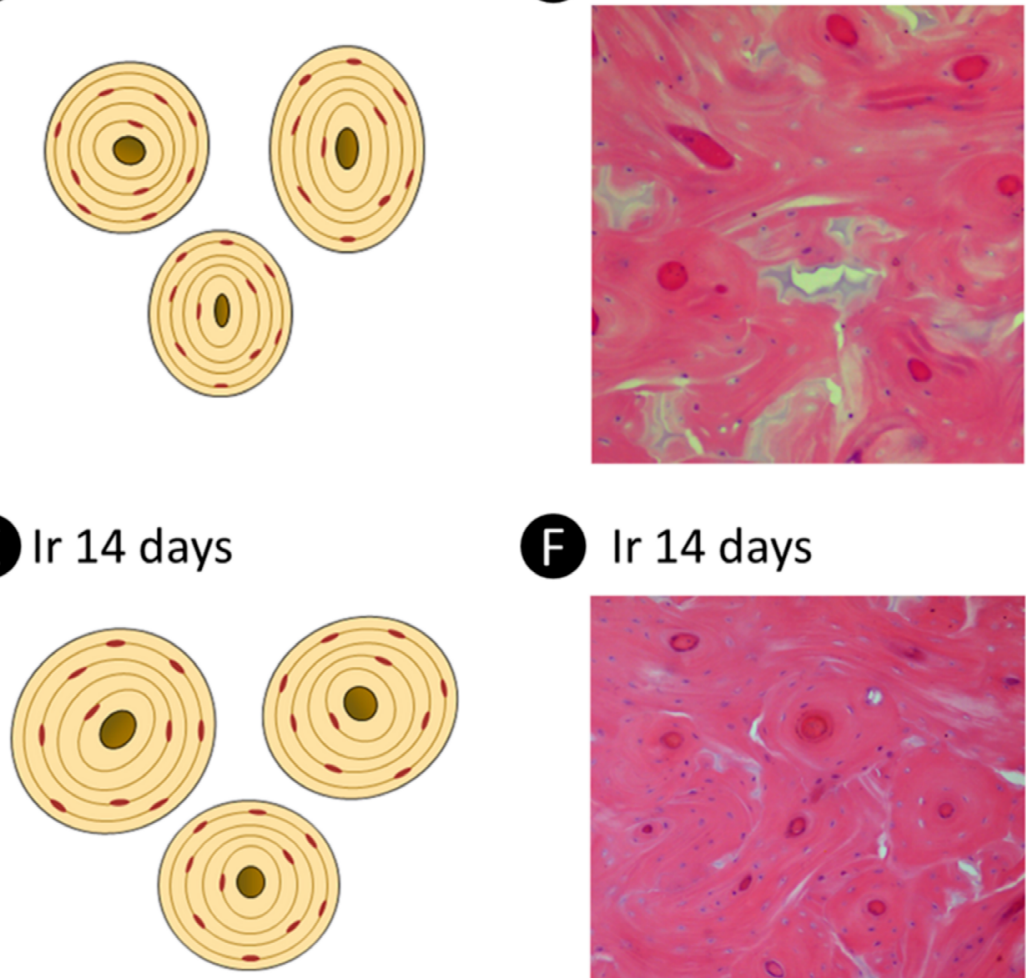

F Ir 14 days

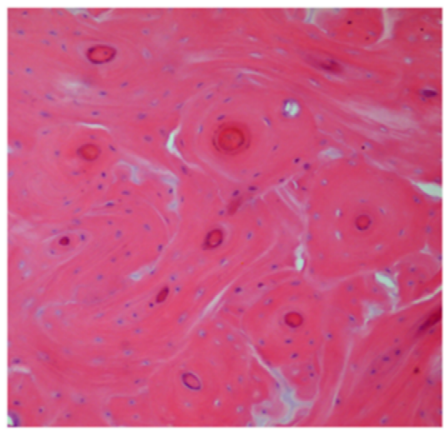

(H) Ir 21 days
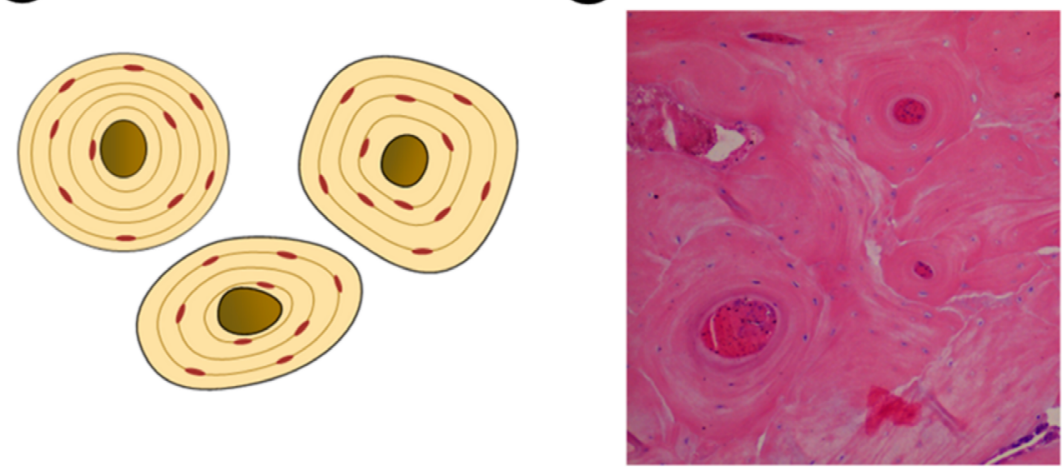

Figure 5 Schematic representation of the size and shape variation in the osteons and Haversian canal for each group (A: Nir; C - Ir 7 days; E - Ir 14 days; G - Ir 21 days), and microphotographs of the corresponding histological sections (B: Nir; D - Ir 7 days; F - Ir 14 days; H - Ir 21 days; Hematoxylin and Eosin stain histological sections; original magnification of 20x). 
and/or maturation due to heterogeneity in morphology and color shades of the osteons. However, a limitation in our evaluation was the use of Hematoxylin and Eosin stain, which is not a common used stain for osteon analysis and does not allow differentiating mineralization stages. The chosen stain was used because is easy access and low costs. Anyway, our objective was to assess the osteon morphology, and that was enough to evaluate the osteons and discover that after radiation the osteons revealed differences in size and shape, also containing smaller Haversian channels.

In conclusion, cortical bone can be affected by ionizing radiation and it appears to be time dependent. In the initial days, the number of intracortical vascular channels decrease, and the osteons revealed to be smaller at this first period, also containing smaller channels. As time increase, similar conditions between control and irradiated groups, mostly at 21 days, were found, suggesting that cortical bone returns to its regular conformation after a certain period.

\section{Resumo}

Com o objetivo de avaliar a microarquitetura óssea cortical e a morfologia dos osteons após irradiação, foram utilizados doze coelhos machos da Nova Zelândia. Os animais foram divididos: grupo controle (sem radiação-NIr); e 3 grupos irradiados, sacrificados após: 7 (Ir7d); 14 (Ir14d) e 21 (Ir21d) dias. Foi utilizada uma dose única de radiação de $30 \mathrm{~Gy}$. A microtomografia computadorizada analisou a microarquitetura cortical: espessura cortical (CtTh), volume ósseo (BV), porosidade total (Ct.Po), porosidade intracortical (CtPo-Cl), número de canal/ poro (Po.N), dimensão fractal (DF) e grau de anisotropia (Ct.DA). Após a varredura, a morfologia dos osteosn foi avaliada histologicamente por meio de: Área e perimetro do osteon (0.Ar; 0.p) e dos canais de Havers (C.Ar; C.p). A análise microtomográfica foi realizada por ANOVA, seguida pelos testes de Tukey e Dunnet. As análises morfológicas do osteon foram realizadas por Kruskal-Wallis e testadas por Dunn. A espessura cortical foi diferente $(p<0,010)$ entre os grupos controle e irradiados, com córtex mais espesso no Ir7d $(1,15 \pm 0,09)$. A porosidade intracortical revelou diferenças significativas $(p<0,001)$ entre os grupos irradiados e o controle, com menor valor para Ir7d $(0,29 \pm 0,09)$. 0 volume ósseo foi menor no Ir14d em relação ao controle. Área e perímetro do osteon foi diferente $(p<0,0001)$ entre o controle e Ir $7 d$. Os canais haversianos também revelaram valores mais baixos $(p<0,0001)$ em Ir $7 \mathrm{~d}(80.57 \pm 9.3 ; 31.63 \pm 6.5) \mathrm{em}$ relação ao controle e demais grupos irradiados. A microarquitetura cortical é afetada pela radiação e os efeitos parecem ser dependentes do tempo, principalmente em relação à morfologia dos osteons nos dias iniciais. A estrutura cortical em Ir $21 \mathrm{~d}$ revelou semelhanças com o controle, sugerindo que a microarquitetura se assemelha à condição normal após um período.

\section{Acknowledgments}

The authors are grateful to the Department of Clinical Oncology at Federal University of Triângulo Mineiro (UFTM), MG, Brazil. Funding: This study was financed in part by the Coordenação de Aperfeiçoamento de Pessoal de Nivel Superior - Brasil (CAPES) - Finance Code 001 and Fundação de Amparo à Pesquisa do estado de Minas Gerais (FAPEMIG).

\section{References}

1. Bentzen SM. Preventing or reducing late side effects of radiation therapy: Radiobiology meets molecular pathology. Nat Rev Cancer 2006:6:702-713.

2. Tanaka TI, Chan HL, Tindle DI, Maceachern M, Oh TJ. Updated clinical considerations for dental implant therapy in irradiated head and neck cancer patients. J Prosthodont 2013;22:432-438.
3. Vanderpuye V, Goldson A. Osteoradionecrosis of the mandible. J Natl Med Assoc 2000;92:579-584.

4. Rabelo GD, Beletti ME, Dechichi P. Histological analysis of the alterations on cortical bone channels network after radiotherapy: A rabbit study. Microsc Res Tech 2010;73:1015-1018.

5. Soares PBF, Soares CJ, Limirio PHJO, de Jesus RNR, Dechichi P, Spin-Neto $R$, et al. Effect of ionizing radiation after-therapy interval on bone: histomorphometric and biomechanical characteristics. Clin Oral Investig 2019;23:2785-2793.

6. Limirio PHJO, Soares PBF, Emi ETP, Lopes CCA, Rocha FS, Batista JD, et al. lonizing radiation and bone quality: time-dependent effects. Radiat Oncol 2019;14:15.

7. Bala $Y$, Zebaze $R$, Seeman E. Role of cortical bone in bone fragility. Curr Opin Rheumatol 2015;27:406-413.

8. Gasser JA, Kneissel M. Bone physiology and biology. in: bone toxicology, molecular and integrative toxicology. Smith S, Varela A, Samadfam R (eds). Springer International Publishing 2017;27-83.

9. Zebaze RM, Ghasem-Zadeh A, Bohte A, Iuliano-Burns S, Mirams M, Price $\mathrm{Rl}$, et al. Intracortical remodelling and porosity in the distal radius and post-mortem femurs of women: a cross-sectional study. Lancet 2010;15;375:1729-1736.

10. Bernhard A, Milovanovic P, Zimmermann EA, Hahn M, Djonic D, Krause $M$, et al. Micro-morphological properties of osteons reveal changes in cortical bone stability during aging, osteoporosis, and bisphosphonate treatment in women. Osteoporos Int 2013;24:2671-2680.

11. Chapurlat RD, Delmas PD. Bone microdamage: a clinical perspective. Osteoporos Int 2009;20:1299-1308.

12. Dominguez VM, Agnew AM. Microdamage as a Bone Quality Component: Practical Guidelines for the Two-Dimensional Analysis of Linear Microcracks in Human Cortical Bone. JBMR Plus 2019;17;3:e10203.

13. Pazzaglia UE, Congiu T, Pienazza A, Zakaria M, Gnecchi M, Dell'orbo C. Morphometric analysis of osteonal architecture in bones from healthy young human male subjects using scanning electron microscopy. J Anat 2013;223:242-254.

14. Faingold A, Cohen SR, Wagner HD. Nanoindentation of osteonal bone lamellae. J Mech Behav Biomed Mater 2012;9:198-206.

15. Ma $Y$, Shen G. Distraction osteogenesis after irradiation in rabbit mandibles. Br J Oral Maxillofac Surg 2012;50:662-667.

16. Lee SH, Kim JY, Lee KC, Nam JS, Choi J, Lee SH, et al. Establishment of linear accelerator-based image guided radiotherapy for orthotopic 4T1 mouse mammary tumor model. Lab Anim Res 2014;30:64-72.

17. King $M$, Casarett $G$, Weber D. A study of irradiated bone: I. histopathologic and physiologic changes. J Nucl Med 1979;20:11421149.

18. Batista JD, Zanetta-Barbosa D, Cardoso SV, Dechichi P, Rocha FS Pagnoncelli RM. Effect of low-level laser therapy on repair of the bonecompromised by radiotherapy. Lasers Med Sci 2014;29:13-18.

19. Nyaruba MM, Yamamoto I, Kimura H, Morita R. Bone fragility induced by $\mathrm{X}$-ray irradiation in relation to cortical bone-mineral content. Acta Radiol 1998;39:43-46.

20. Cooper DM, Kawalilak CE, Harrison K, Johnston BD, Johnston JD. Cortical bone porosity: what is it, why is it important, and how can we detect it? Curr Osteoporos Rep 2016;14:187-198.

21. Fajardo LF, Berthrong M, Anderson RE. Radiation Pathology. J Clin Pathol 2001;55:480.

22. Schiegnitz $\mathrm{E}, \mathrm{Al}-\mathrm{Nawas} \mathrm{B}$, Kämmerer PW, Grötz KA. Oral rehabilitation with dental implants in irradiated patients: a meta-analysis on implant survival. Clin Oral Investig 2014;18:687-698. Review. Erratum in: Clin Oral Investig 2015;19:1693.

23. Ascenzi MG, Roe AK. The osteon: the micromechanical unit of compact bone. Front Biosci (Landmark Ed) 2012;1:1551-1581.

24. Qiu S, Fyhrie DP, Palnitkar S, Rao DS. Histomorphometric assessment of Haversian canal and osteocyte lacunae in different-sized osteons in human rib. Anat Rec A Discov Mol Cell Evol Biol 2003;272:520-525. 